\title{
Exploring Teaching Reform of Electronic Technology Courses Design
}

\author{
Heng Wang ${ }^{\mathrm{a}}$, Peng Deng \\ School of Electronics and Information Engineering, Jingchu University of Technology, Jingmen, 448000, \\ China \\ awanghengwh@126.com
}

Keywords: talent demand, theoretical knowledge, practical ability, teaching content

\begin{abstract}
With the development of the times, on the basis of requiring talented people to possess solid theoretical knowledge, talents are required to have certain practical ability to meet the actual needs of the work. For the electronic technology courses, the electronic technology curriculum design is a practical teaching content, and is an important part of personnel training objectives. In view of this, this paper has explored the research and practice of the reform of electronic curriculum design content in order to provide reference and reference for the related work and research.
\end{abstract}

\section{Introduction}

The course "Basic Electronics Technology" is one of the most important basic technical courses for electrical major, and is a required course for various major in electrical, electronics and information. The course not only requires a higher theoretical basis, but also has practical applicability. Electronic technology curriculum design is an important part of teaching practice linked with theory and practice. It plays an important role in practice teaching system with its comprehensiveness, novelty and innovation, and becomes a key to cultivating students' abilities to practice, design and solve problems independently important part.

\section{Problems}

At present, according to our school automation engineering professional teaching plan, electronic technology curriculum design arrangements in sophomore next semester, curriculum design, the electrical and electronic internship. The two sessions are scheduled for two weeks, completed in two laboratories, respectively, by the two teachers were instructed. Due to these factors, the subject of course design is essentially irrelevant to the content of the e-internship. The goal of course design is to design the circuit according to the design, connect the designed circuit in the experiment box and debug the result, and there is no hands-on making, nor the opportunity to weld the circuit designed by ourselves. In fact, there is a big difference between the commissioning circuit and the debug circuit. There are many practical problems in the debugging process. Some of the problems are related to the design. Electrical and electronics internship is usually the teacher sent to students printed circuit board finished, students in accordance with the design of the circuit diagram soldered components, the final commissioning success. Students do not fully understand the function of each circuit module. Second, the mode of curriculum design restricts the selection of teachers, the design topics and design methods are often single, and the students should finish the design within the stipulated time and prescribed laboratory, which limits the creativity of students. Therefore, it is an important aspect of current curriculum design and teaching reform to change the model of curriculum design, improve the efficiency and quality of curriculum design, enhance the students' ability of innovation and engineering practice.

\section{Electronic Technology Curriculum Design Content Reform to meet the Development needs of Students}

With the development of the times, the actual situation of students is also changing. The original 
electronic technology curriculum design has been unable to adapt to the actual situation of modern students, unable to meet the development needs of students. For example, The original design of electronic technology courses, the design time is usually 15 days, and most of the subject of curriculum design teachers to determine, and then, a circuit of welding and debugging students, the basic teaching process has not changed and long-term innovation, a Repeated use of the subject for many years, the ongoing era and students, the lack of new ideas and attractive topics, it is difficult to stimulate students' interest in learning, resulting in students can not produce enthusiasm for learning, which led to students tired of learning emotions, causing students to plagiarism Problems, leading to teaching failure, unable to achieve teaching goals. In addition, the teaching method is single and the teaching mode is fixed, which also limits the development of students.

\section{Electronic Technology Curriculum Design Content Reform to meet the Requirements of the Times of the Development}

In the electronic age, in the electronic technology teaching, only by introducing the new technology into the classroom, combined with the teaching content, and constantly improve the experimental content system in order to ensure the teaching of the times and practicality in order to cultivate a spirit of the times, master advanced technology, And can apply the technology to the compound talent in practice to meet the needs of the students to meet the requirements of the times. Therefore, the reform of electronic technology curriculum design content is of realistic and practical significance. It is an inevitable trend of curriculum development as well as an era Proposed new requirements. As a more novel teaching model, micro class is the resource expansion and supplement of the traditional teaching process. Its characteristics of interaction, short and mobile make it compatible with the learning needs of vocational college students, and at the same time, it is closely related to the development of electronic technology teaching and industry. Therefore, it is of great significance for deepening the reform of higher vocational education and realizing the innovation of practice. It is possible to meet the needs of students at different levels. In higher vocational colleges, students' desire for knowledge and learning enthusiasm are not high. They need to stimulate their interest in learning and exercise their ability to learn independently. The micro lesson is based on interactive online mode, so that teachers can find students' shortcomings timely and facilitate their tutoring, and at the same time, improve their curiosity and enthusiasm. The way of learning can be diversified. The introduction of micro courses in electronic technology courses can achieve the diversification of learning methods, so that students are more interested and willing to carry out the inquiry of knowledge. Increase the time and space of learning to make up for the lack of time. The use of micro courses in electronic technology courses can break the limits of space and time, improve the effect of teaching, and realize the process of deep learning.

\section{Problems Existing in the Teaching Process of Electronic Technology Course}

In the traditional teaching of electronic technology course, many colleges in the occupation are the use of traditional injection type teaching mode, "listen" and "remember" learning for students to teachers to teach the implementation of mechanical absorption in the process of learning, it is difficult for students to explore learning interest, so it it is very difficult to cultivate the ability of scientific thinking ability and independent innovation. The students of five years higher vocational colleges is relatively weak, for the study of theoretical knowledge is the lack of interest in the traditional teaching mode, teachers are teachers occupy the dominant position, according to their views and experience transmitted to the students' abstract knowledge, but the students' perception and thinking, can not mobilize the enthusiasm of students learning. At the same time, in order to complete the teaching task, the course arrangement exceeds the load, which results in the teaching effect is not ideal. Because more traditional teaching methods are adopted, and equipment and teaching fields are limited, so students' opportunities for hands-on practice are limited. These problems will affect the overall effect of teaching, which leads students to think that knowledge in curriculum is too abstract. In the process of expanding enrollment scale in vocational colleges, all 
kinds of hardware facilities needed for practice cannot follow up properly, resulting in the lack of experimental equipment and the old situation, which leads many students to be unable to practice, and it is difficult to improve practical skills. There is no reasonable evaluation form in the traditional teaching form, more rigid, more conventional types, just fill in the blanks, selection, calculation, quizzes and other forms, which can only examine the concepts, and can make students understand the knowledge, but also not very good reflect the real quality of teaching.

\section{The Choice of Topics Focus on Practicality and Fun}

In the design of electronic technology curriculum, we must base ourselves on the actual situation of the students when choosing a subject, and at the same time, we should fully consider the matching degree between the subject and the theoretical knowledge to be taught. In addition, we should also consider whether the subject is practical and interesting Sexual, interesting is to ensure that students interest in learning, practicality is to ensure that practice has practical significance, both can guarantee that the design content to meet the teaching requirements, but also to meet the actual needs of production. For example, the topics can be formulated according to students' actual conditions. Students can then practice the assembly of voice-activated switches that can be used in real life or power switches that can switch the power supply in time when voltage is abnormal. Student assembly burglar alarm and so on. In addition, teachers can also choose new and interesting new topics such as music lantern control, which in turn stimulates students 'learning desires and gives full play to students' creativity and application ability of knowledge.

\section{Pay Attention to the Flexible use of Comprehensive Theoretical Knowledge}

In terms of electronic technology curriculum design, its essence is used in life practice, through the study of theoretical knowledge, and ultimately solve the practical problems encountered in life. However, if you want to achieve the goal of solving practical problems, we should pay attention to the flexible application of the theory of curriculum in the design of teaching contents. Specifically, in the process of curriculum design, as students, they should consciously exercise their ability to master and make full use of theoretical knowledge, and develop their own ability to design content independently. In the learning process, students can learn the relevant information, circuit design and component selection, the implementation of circuit installation, to achieve the purpose of consolidating knowledge, improve their ability to use knowledge, to achieve the effective combination of theory and practice. For example, during the design of a digital clock circuit, in order to accomplish the task, a student must complete and summarize all the knowledge of the scattered digital circuits he or she has in hand, and then apply various theoretical knowledge in practice. Through repeated exercises, Effectively develop students' ability to design and analyze, tap students' inherent potential and enhance students' comprehensive abilities and qualities.

\section{Take Full account of Professional Characteristics and Needs}

To broaden students' horizons, students are encouraged to have a keen interest in what they have learned. Teachers should consider professional characteristics and their professional needs as factors to consider when designing content. For example, "motor speed system" design, on the one hand, the design can be widely applied to the field of industrial control speed control system which; on the other hand, the design of the generator and the design of the voltage computer , But also with the content of teaching electronic technology courses are closely linked. Such design content, to some extent, can enhance students 'professional identity, help to learn interest, but also can open up

students' knowledge horizons. In addition, students can further follow-up study, lay a solid professional foundation to adapt to future job positions. 


\section{Method of Reform}

Enrich the experiment content and design method of curriculum design, and discuss the dimensional teaching method. Starting from increasing teaching content and related knowledge, we should build a systematic and scientific curriculum system. The new course system includes not only analog and digital electronics related topics but also circuit design topics as well as advanced technologies such as programmable logic devices, computer-aided design CAD and virtual simulation and plate making Rich, advanced. A wealth of practical teaching content, the curriculum design content is systematic, scientific, feasible and complete. In the teaching methods, using a variety of methods and adapt to the content. In the teaching process using inspiration and problem-based inquiry teaching methods. In the selection of topics, change the past, the stereotyped design topics, and strive to be modern, practical and diverse. Students can also design their own design topics to further stimulate their design initiative and creativity. In order to give consideration to the training of students' practical engineering skills and the cultivation of innovative awareness, students are encouraged to design a number of programs on the selected topics. Both the simple circuit design and novel circuit design solutions are available. Systems composed of circuit elements Circuit and other programs.

Development of electronic technology curriculum design syllabus and preparation of curriculum design guide. Curriculum design syllabus mainly consider the following aspects. Establish the position and task of electronic technology course design teaching, clear the guiding ideology of teaching reform of "thick foundation, wide caliber, strong practice, emphasis on quality and innovation", the goal of reform and the principles to be followed in the reform. Highlight the students' ability to innovate and practice skills, according to the training objectives and training levels, planning and designing new teaching content, optimizing the course structure, strengthening the cross-cutting and integration of different disciplines so that the curriculum design of electronic technology curriculum closely follow the technology Economic and social development. The achievements of the practical teaching reform over the past few years have been concretely implemented in teaching. The new teaching system should be constructed by comprehensively considering the requirements of knowledge, ability and quality. Consider the modern teaching methods, make full use of modern teaching media, the use of computer simulation technology, online virtual experiment and other forms of experimental means. Develop a set of e-technology course design questions, the contents of the question bank is rich. The topic is comprehensive, interesting, novelty, scientific, depth and breadth. The compilation of electronic technology curriculum design guide is intended to allow students to participate in the entire process of research and design from access to information, design lines, computer software simulation, download, hardware circuit lap and debugging. To provide students with the necessary design ideas, design routes, block diagrams and so on. The title of the exam bank only typical examples, training students ability, independent design ability, engineering ability, innovation ability.

Reform assessment methods and improve the assessment mechanism. Establishing and perfecting the grading system is the key to ensure the teaching quality of curriculum design. The past assessment methods only look at the results, regardless of the process, the drawback is the teacher's subjectivity, the assessment of the standard can not be quantified, it is difficult to truly reflect the true level of students. Therefore, several aspects should be based on the comprehensive evaluation of students' abilities. Whether the program is new and feasible. Practical ability. Complete design report. Through the combination of essay, practice and defense, the results of the electronic technology curriculum design can be comprehensively evaluated, so as to be comprehensive, objective and fair.

Due to the construction of the new curriculum system, the integration and optimization of the electronic technology curriculum design and the teaching content of electric and electronic internships, practical steps to increase practice cross, time schedule is compact, therefore, involved in the three laboratories: CAD lab, electronic technology Laboratories and electrical and electronic laboratories must adopt a comprehensive open management model to ensure that the curriculum 
design is completed efficiently and with high quality. Electronic technology curriculum design is an important teaching link for undergraduate teaching in electrical specialty. In recent years, with the revision of the new teaching plan, the proportion of curriculum design in the whole teaching plan has obviously increased. The planned and high quality of curriculum design and training not only helps students to gain a deeper understanding of the basic theory courses, but more importantly, provides students with an opportunity for independent design and practice. Students through the search for information, design circuit, installation and commissioning, finishing summary and other links, enhance the design and development capabilities and innovative practical ability. Therefore, how to carry out the course design and improve the teaching quality of course design is a topic that every college educator should care about and study seriously.

\section{References}

[1] F.H.S, P.R.Y. Research and Practice of Electronic Technology Courses Design Content Reform [J]. Lab Research and Exploration, 2012 (1): 108-110.

[2] W.X, Z.X, X.H. Research and Practice on Teaching Reform of Electronic Technology Course Design [J]. Experimental Technology and Management, 2014 (7): 180-181.

[3] Y.M.Q, L.H. Educational Reform and Practice in Course Design of Electronic Technology [P]. Journal of Tianjin Polytechnic Normal University, 2016 (12): 40-42.

[4] B.H.Y, C.R, H.Y. Cultivation of innovative ability in the practice of electrical and electronic [J]. Journal of North China Institute of Aerospace, 2012 (8): 46-48.

[5] P.J. Electronic Technology Course Design Guide [M]. Higher Education Press, 2012 (5): 1-36. 